\title{
Population genetics of swamp eel in the Yangtze River: comparative analyses between mitochondrial and microsatellite data provide novel insights
}

\author{
Huaxing Zhou ${ }^{\text {Equal first author, } 1}$, Yuting Hu ${ }^{\text {Equal first author, } 1}{ }^{1}$, He Jiang ${ }^{\text {Corresp., } 1}$, Guoqing Duan ${ }^{1}$, Jun Ling ${ }^{1}$, Tingshuang Pan ${ }^{1}$, \\ Xiaolei Chen ${ }^{1}$, Huan Wang ${ }^{1}$, Ye Zhang ${ }^{1}$ \\ ${ }^{1}$ Anhui Key Laboratory of Aquaculture and Stock Enhancement, Fisheries Research Institution, Anhui Academy of Agricultural Sciences, Hefei, China \\ Corresponding Author: He Jiang \\ Email address: kenc7c7c7@126.com
}

The swamp eel (Monopterus albus) is a typical sex reversal fish with high economic value. Several phylogeographic studies have been performed using various markers but comparative research between mitochondrial and nuclear markers is rare. Here, a finescale study was performed across six sites along the Yangtze River including three sites on the main stem and three sites from tributaries. A total of 180 swamp eel individuals were collected. Genetic structure and demographic history were explored using data from two mitochondrial genes and eight microsatellite loci. The results revealed the samples from tributary sites formed three separate clades which contained site-specific lineages.

Geographic isolation and the habitat patchiness caused by seasonal cutoff were inferred to be the reasons for this differentiation. Strong gene flow was detected among the sites along the main stem. Rapid flow of the river main stem may provide the dynamic for the migration of swamp eel. Interestingly, the comparative analyses between the two marker types was discordant. Mitochondrial results suggested samples from three tributary sites were highly differentiated. However, microsatellite analyses indicated the tributary samples were moderately differentiated. We conclude this discordance is mainly caused by the unique life history of sex reversal fish. Our study provides novel insights regarding the population genetics of sex reversal fish. 
1 Population genetics of swamp eel in the Yangtze River: comparative analyses between mitochondrial and microsatellite data provide novel insights

4 Huaxing Zhou' ${ }^{1}$, Yuting Hu$\left.{ }^{1(}\right)$, He Jiang ${ }^{1 凶}$, Guoqing Duan ${ }^{1}$, Jun Ling ${ }^{1}$, Tingshuang Pan ${ }^{1}$, Xiaolei Chen ${ }^{1}$, Huan Wang ${ }^{1}$, Ye Zhang ${ }^{1}$

${ }^{1}$ Anhui Key Laboratory of Aquaculture and Stock Enhancement, Fisheries

ఐ: Corresponding author:

11 He Jiang

12 The Nongkenan road, Hefei, Anhui, 230031, China

13 Email address: kenc7c7c7@126.com

(1): These authors contributed equally to this work 


\section{Abstract}

The swamp eel (Monopterus albus) is a typical sex reversal fish with high economic value. Several phylogeographic studies have been performed using various markers but comparative research between mitochondrial and nuclear markers is rare. Here, a finescale study was performed across six sites along the Yangtze River including three sites on the main stem and three sites from tributaries. A total of 180 swamp eel individuals were collected. Genetic structure and demographic history were explored using data from two mitochondrial genes and eight microsatellite loci. The results revealed the samples from tributary sites formed three separate clades which contained site-specific lineages. Geographic isolation and the habitat patchiness caused by seasonal cutoff were inferred to be the reasons for this differentiation. Strong gene flow was detected among the sites along the main stem. Rapid flow of the river main stem may provide the dynamic for the migration of swamp eel. Interestingly, the comparative analyses between the two marker types was discordant. Mitochondrial results suggested samples from three tributary sites were highly differentiated. However, microsatellite analyses indicated the tributary samples were moderately differentiated. We conclude this discordance is mainly caused by the unique life history of sex reversal fish. Our study provides novel insights regarding the population genetics of sex reversal fish.

Keywords: Monopterus albus; Sex reversal; Population genetics; Mitochondrial and nuclear markers 


\section{Introduction}

The swamp eel (Monopterus albus) is a typical sex reversal fish, belonging to the family Synbranchidae, which usually inhabits swamps, ponds and rice fields (Nelson, Grande \& Wilson, 2016). Due to its high nutritional value and good taste, the swamp eel is used as a significant aquatic food in China. In 2018, 0.32 million tons of swamp eel were produced by Chinese aquaculture (data from The Ministry of Agriculture of China, 2019).

With the development of swamp eel farming, population genetic research of the wild eel became a hot topic, which has been used to guide the genetic breeding and swamp eel aquaculture. Several studies have used different markers including microsatellites, mitochondrial sequences and Inter-Simple Sequence Repeats (ISSR) to explore swamp eel population genetics (Lei et al., 2012; Li et al., 2013; Liang et al., 2016). Previous studies suggested a rapid decrease of wild swamp eel caused by the large use of pesticides and over-exploitation (Li et al., 2013; Liang et al., 2016). Cultured populations were genetically less diverse than wild populations. Due to farm escapes, the populations of wild swamp eel suffer from genetic homogenization and degeneration of genetic characters (Li et al., 2013). Thus, further research of population genetics and dynamics are necessary to protect the wild swamp eel.

Monopterus albus is a sex reversal fish with a unique life history (Liu, 1944; Mazzoni et al., 2018; Qu, 2018). It starts the reproductive cycle as a functional female. During 1 to 1.5 years of age, females obtain well-developed ova. After spawning, the swamp eel's sex is reversed from female to male. The intersexes appear in the two-year-old age class. Then it lives as male without sex reversal (Liem, 1963). Generally, swamp eels can live to 6-8 years. Mitochondrial DNA is maternally inherited. For this reason, the inheritance patterns of protogynous hermaphrodites differ to that of species that do not practice sex reversal (Coscia et al., 2013). Therefore, it may be important to include both nuclear and mitochondrial markers to explore the population genetics of sex reversal fish.

This fine-scale study was performed across six sites along the Yangtze River 
66 including three sites on the main stem and three sites from tributaries. Subsequently, the

67 genetic structure of these six sampling sites was explored, using sequence from two 68 mitochondrial genes and eight microsatellite loci. Here, we show how different types of 69 molecular markers can provide new insights regarding the population genetics of sex 70 reversal fish.

\section{Materials \& Methods}

\section{Ethics statement and Sample collection}

Procedures involving animals and their care were approved by the Animal Care and Use Committee of Anhui Academy of Agricultural Sciences under approval number 201003076. Field experiments were approved by Fisheries Bureau of Anhui (project number: FB/AH 2017-10).

A total of 180 individuals were collected using net from six sites along the Anhui basin of the Yangtze River (Table S1). Sampling sites from tributaries of the Yangtze River included Dang Tu (DT), Fan Chang (FC) and Huai Ning (HN); sampling sites from the main stem of the Yangtze River included Wu Wei (WW), Gui Chi (GC) and Wang Jiang (WJ) (Fig. 1).

\section{DNA extraction and Marker genotyping}

Total genomic DNA was extracted from muscle tissue using a standard phenol/chloroform procedure via proteinase K digestion (Sambrook, Fritsch \& Maniatis, 1989), and then kept at $-20^{\circ} \mathrm{C}$ for PCR amplification.

The mitochondrial cytochrome c oxidase subunit I ( $\mathrm{CO}$ ) gene and cytochrome b (Cyt b) gene were chosen. Two pairs of primers were designed here for the amplification (Table S2). PCR were conducted in $50 \mu \mathrm{L}$ reaction mixtures containing $200 \mathrm{ng}$ template DNA, $5 \mu \mathrm{L} 10 \times$ buffer (TaKaRa, Dalian, China), $4 \mu \mathrm{L} \mathrm{MgCl}_{2}(2.5 \mathrm{~mol} / \mathrm{L}), 3 \mu \mathrm{L}$ dNTP $(2.5$ $\mathrm{m} \mathrm{mol} / \mathrm{L}), 2 \mu \mathrm{L}$ of each primer $(5 \mu \mathrm{mol} / \mathrm{L})$, and $1 \mathrm{U}$ Taq DNA polymerase $(5 \mathrm{U} / \mu \mathrm{L}$, TaKaRa). PCR conditions were as follows: initial denaturation $\left(95^{\circ} \mathrm{C}, 1 \mathrm{~min}\right)$, then 35 cycles of denaturation $\left(94^{\circ} \mathrm{C}, 50 \mathrm{~s}\right)$, primer annealing $\left(55^{\circ} \mathrm{C}, 45 \mathrm{~s}\right)$, and elongation $\left(72^{\circ} \mathrm{C}\right.$, 
$931 \mathrm{~min})$ and a final extension $\left(72^{\circ} \mathrm{C}, 10 \mathrm{~min}\right)$. All fragments were sequenced in both

94 directions with an ABI3730 automated sequencer (Invitrogen Biotechnology Co., Ltd, USA). Then these two gene sequences were combined for subsequent analyses.

Eight unlinked polymorphic microsatellite loci were selected from previous studies (Table S1) (Lei et al., 2012; Li et al., 2007; Zhuo et al., 2011). PCR were conducted in 50 $\mu \mathrm{L}$ reaction mixtures containing $200 \mathrm{ng}$ template DNA, $5 \mu \mathrm{L} 10 \times$ buffer (TaKaRa, Dalian, China), $4 \mu \mathrm{L} \mathrm{MgCl} 2$ (2.5 mol/L), $2.5 \mu \mathrm{L} \mathrm{dNTP}(2.5 \mathrm{~m} \mathrm{~mol} / \mathrm{L}), 2 \mu \mathrm{L}$ of each primer $(5 \mu \mathrm{mol} / \mathrm{L})$, and $1 \mathrm{U}$ Taq DNA polymerase ( $25 \mathrm{U} / \mu \mathrm{L}$, TaKaRa). PCR conditions were as follows: initial denaturation $\left(95^{\circ} \mathrm{C}, 5 \mathrm{~min}\right)$, then 32 cycles of denaturation $\left(94^{\circ} \mathrm{C}, 30 \mathrm{~s}\right)$, primer annealing $\left(57^{\circ} \mathrm{C}, 60 \mathrm{~s}\right)$, and elongation $\left(72^{\circ} \mathrm{C}, 90 \mathrm{~s}\right)$ and a final extension $\left(72^{\circ} \mathrm{C}, 5 \mathrm{~min}\right)$. Genotypes were detected by ABIPRISM 3730 .

\section{Data analyses}

\section{Mitochondrial sequence}

Sequences were assembled by DNASTAR Lasergene package. Subsequent homologous alignment was performed by Mafft v.7 online program (https://mafft.cbrc.jp/alignment/software/) (Katoh, Rozewicki \& Yamada, 2017).

Haplotype and nucleotide diversity were estimated using DNAsp V.6 (Rozas et al., 2017). A haplotype network was constructed using Median Joining (MJ) in NETWORK v.5.0 (Bandelt, Forster \& Röhl, 1999). Analysis of Molecular Variance (AMOVA) was performed using Arlequin v.3.11 (Excoffier, Laval \& Schneider, 2005). Genetic variation within and among sampling sites was assessed. Pairwise $F_{s t}$ was estimated in order to evaluate the levels of population differentiation (Slatkin and Barton, 1989) and the $P$ values were corrected using multiple testing.

The demographic history was explored using three approaches, e.g., neutrality tests, mismatch distribution and Bayesian Skyline Plots (BSP) analyses. Tajima's $D$ (Tajima, 1989 ) and Fu's $F_{\mathrm{s}}(\mathrm{Fu}, 1997)$ values were calculated using DNAsp V.6.Mismatch distribution analyses were performed using Arlequin v.3.11 (Rogers \& Harpending, 1992). The expansion time was calculated by the $\mathrm{T}$ value with the equation $\mathrm{T}=2 \mu \mathrm{t}$, where $\mu$ 
121 represents the nucleotide mutation rate and t represents the estimated expansion time.

122 BSP analysis was performed using Beast v1.10.4 (Suchard et al., 2018) under an 123 uncorrelated relaxed clock mode for $5 \times 10^{7}$ generations.

\section{Microsatellites data}

125 The results of 8 microsatellites loci were read using GeneMarker (Holland \& Parson, 126 2011) and reformatted using Convert v.1.31 (Glaubitz, 2004). Hardy-Weinberg 127 equilibrium (HWE) tests were performed using Popgene v 1.32 (Yeh et al., 1999). 128 Expected and observed heterozygosity were calculated with Arlequin v.3.11 (Rogers \& 129 Harpending, 1992). AMOVA was implemented with Arlequin. Pairwise $F_{s t}$ was computed 130 based on Slatkin's method (Slatkin \& Barton, 1989). The geographical and genetic 131 distance between sample sites was measured by GPS and Popgene v 1.32, respectively. 132 The correlation between geographical and genetic distance was analyzed using Pcord v 1335 (Grandin, 2006).

134 Population structure was estimated using an MCMC (Markov Chain Monte Carlo) 135 algorithm as implemented in Structure v.2.3.3 (Hubisz et al., 2009). The number of 136 clusters $(\mathrm{K})$ was calculated under $1 \times 10^{6}$ iterations with 10 replications and the optimal 137 number of $\mathrm{K}$ was deduced by Structure Harvester Web v.0.6.94 (Evanno, Regnaut \& 138 Goudet, 2005; Earl, 2012).

139

140

\section{Results}

\section{Mitochondrial genes}

A total of 1752 bp of mitochondrial sequence (COI 665 bp, Accession number: MN097948 - MN098127; Cyt b 1087 bp, Accession number: MN098128 - MN098307) were obtained for analyses. The contents of the bases A, T, G and C were $24.6 \%, 29.3 \%$, $14.6 \%$ and $31.5 \%$ respectively, which showed obvious anti-G bias (Saccone et al., 1999).

The 180 mitochondrial sequences corresponded to 86 distinct haplotypes (Table 1). All haplotypes were divided into four clades based on MJ method (Fig. 2). Clade A was the largest one which contained samples from five sampling sites. Haplotype $5(\mathrm{H}-5)$ had the largest number of shared individuals, and its central placement in the network 
149 suggests that this is the ancestral haplotype. The other three clades were separated by $15013,47,24$ mutational steps, respectively. Clade B and C only contained samples from the 151 HN and FC sampling sites, respectively. Clade D mainly consisted of DT samples.

152 Haplotype diversity ranged from 0.6620 to 0.9793 and nucleotide diversity ranged 153 from 0.0017 to 0.0148 based on mitochondrial sequence (Table 1). The results of AMOVA 154 showed that genetic variation among sampling sites $(71.23 \%, P<0.001)$ were much 155 higher than the variation within the sampling sites $(28.77 \%, P<0.001)$ (Table $2 a)$. 156 Subsequent $F_{s t}$ values further confirmed this result. Strong gene flow was detected 157 between the main stem sampling sites $\left(F_{s t}=0.0242\right.$ between $\mathrm{GC}$ and WW, $F_{s t}=0.0286$ 158 between WJ and WW, $F_{s t}=0.0305$ between WJ and GC, see Table 3a). And high differentiation was revealed between the tributary sampling sites $\left(F_{s t}=0.3069-0.9431\right)$ (Table 3a). Fu's $F_{\mathrm{s}}$ and Tajima's $D$ tests of main stem samples were significant $(P<0.01)$ but negative. No explicit expansion or decline were revealed for the tributary samples and the Fu's $F_{\mathrm{s}}$ and Tajima's $D$ values except the Tajima's $D$ of FC were not significant (Table 4). Mismatch distribution analysis revealed similar results. The values of sum of squares deviations (SSD) for samples from main stem and DT were not significant $(P>0.05)$, indicating that sudden expansion could not be rejected (Table 4). The BSP analysis suggested the main stem samples had expanded roughly in 0.46 MYA (Fig. 3).

\section{Microsatellite loci}

The eight microsatellite loci amplified unambiguous and repeatable products in the size range expected. All loci were in Hardy-Weinberg equilibrium $(P>0.05)$. High genetic diversity was also supported by microsatellite data. Expected and observed heterozygosity for the six sampling sites were $0.8052-0.8749$ and $0.5958-0.7917$, respectively (Table 1).

Structure results suggested the highest posterior probability for $\mathrm{K}=4$ (Fig. S1). The $\Delta \mathrm{K}$ method revealed four potential genetic clusters, aligning with the three tributaries and all the main stem sites together. Samples from main stem showed high levels of genetic admixture (Fig. 4). 
177

178

179

180

181

182

183

184

185

186

187

188

189

190

191

192

193

194

195

196

197

198

199

200

201

202

203

204

AMOVA was performed using the microsatellite data and suggested that genetic variation was mainly within sampling sites $(94.65 \%, P<0.001)$, opposite to the results from mitochondrial data (Table $2 \mathrm{~b})$. $F_{s t}$ values suggested low levels of differentiation $\left(F_{s t}\right.$ $=0.0005-0.0982)($ Table 3b).

The correlation between genetic and geographic matrixes was assessed using Mantel test (Table S3). The results suggested a significant correlation between them $(r=$ $0.8791, P=0.004)($ Fig. 5).

\section{Discussion}

\section{Population genetics of swamp eel}

High levels of genetic diversity were found across sampling sites at both mitochondrial and microsatellite markers. The genetic diversity level of this study except FC sample site was higher than previous study in the same basin $(\mathrm{Hd}=0.708$ and $\mathrm{Pi}=$ 0.002 based on mitochondrial D-loop sequences) (Liang et al., 2016). The genetic diversity of FC samples was the lowest $(H d=0.6620, P i=0.0017)$. The significant differentiation of three tributary sampling sites was revealed by the population genetic analyses $\left(F_{s t}>0.25\right)$. The haplotype network and structure results suggested the tributary samples formed three separate clades which contained site-specific lineages. Significant correlation between genetic and geographic distance was detected. Interestingly, strong gene flow was detected among the main stem sampling sites and the expansion of main stem samples was detected.

It is well known that the swamp eel is a burrowing fish whose fins are vestigial or absent (Nelson, Grande \& Wilson, 2016). Compared with most fishes, the swimming ability of eel is weak. Thus, we were curious about the reasons for this long-distance gene flow among main stem sampling sites. The flow rate of main stem in Anhui basin range up to $1.0 \mathrm{~m} / \mathrm{s}$ (Guo \& Xia, 2007). Rapid flow provides the dynamic for the migration of swamp eel. The eggs and juvenile fishes can slip downstream to the farther places. However, due to the flat stream gradient and curved channel, the tributary flow becomes slower (Zhang, Li \& Jiang, 2008) and long-distance migration is difficult for swamp eel. 
205 We propose that geographic isolation and the habitat patchiness caused by seasonal

206

207

208

209

210

211

212

213

214

215

216

217

218

219

220

221

222

223

224

225

226

227

228

cutoff are the reasons for the differentiation between tributary samples. The tributary of FC site was much more isolated from the main stem. It connected to the main stem during the wet season and isolated during the dry season. Long-term isolation from the main stem may cause the low genetic diversity of FC samples.

Comparative analyses between mitochondrial and microsatellite data

Analyses of nuclear and mitochondrial markers revealed discordant population structure. Based on mitochondrial data, genetic variation was mainly found among sampling sites. Samples between the tributary sites were highly differentiated $\left(F_{s t}>0.25\right)$ and represented three monophyletic clades. However, microsatellite analyses suggest that the majority of genetic variation is within these sampling sites; samples between the tributary sites were moderately differentiated $\left(0.05<F_{s t}<0.15\right)$. Mean $F_{s t}$ values among six sampling sites based on mitochondrial and microsatellite data were 0.548 and 0.055 , respectively. The mean mitochondrial $F_{s t}$ value $(0.548)$ was almost ten times higher than the $F_{s t}(0.055)$ estimated with microsatellite data.

Our study provided an interesting pattern of discordance between markers for population genetics. According to previous studies, sex-biased dispersal, genetic admixture and lineage sorting may be the potential reasons for the discordance caused by different molecular markers (Funk and Omland, 2003; Qu et al., 2012; Yang et al., 2016; Zarza et al., 2011). Considering the sex reversal in this species, we inferred the unique life history of the swamp eel contributed to this discordance. Initially, the swamp eel is female and provides both mitochondrial and nuclear DNA to the population genetic pool. After spawning, the swamp eel becomes male. Male swamp eels are much bigger and stronger than females. Males could migrate farther and have a higher survival rates, which provides a potential of male sex-biased dispersal. Due to mitochondrial maternal inheritance, male swamp eels only provide nuclear DNA to the population genetic pool (Fig. 6). So male sex-biased dispersal may cause the differences in population structure between the markers. As mentioned above, male stage is much longer than female stage 
233 in the whole life of swamp eel that may cause different genetic frequencies between

234 mitochondrial and nuclear data. The ten-fold difference between mitochondrial and 235 nuclear $F_{s t}$ values also confirmed this hypothesis.

\section{Conclusions}

237 Our study used two data sets, mitochondrial DNA and microsatellites, to explore the 238 demography, genetic variation and population structure of swamp eels. Compare with 239 previous studies, high levels of genetic diversity suggest that swamp eels are an 240 abundant resource in the Anhui basin and have potential commercial value. Samples from 241 each tributary site in this study should be treated as an independent genetic unit. The 242 unique sex reversal life history of the swamp eel may be significant factor affecting the 243 population genetic structure and may generate the discordance we found between 244 different molecular markers. Our study provides novel insights regarding the population 245 genetics of sex reversal fish.

Acknowledge

We thank Assoc. Prof. Lee Rollins, Adomas Ragauskas, Joana Robalo and Dr. Yangyang Liang for their constructive comments. 


\section{References}

252 Bandelt HJ, Forster P, Röhl A. 1999. Median-joining networks for inferring intraspecific phylogenies. Molecular biology and evolution 16: 37-48.

Coscia I, Chopelet J, Waples RS, Mann BQ, Marian S. 2016. Sex change and effective population size: implications for population genetic studies in marine fish. Heredit 117: 251 .

Earl DA. 2012. STRUCTURE HARVESTER: a website and program for visualizing STRUCTURE output and implementing the Evanno method. Conservation genetics resources 4: 359-361.

Evanno G, Regnaut S, Goudet J. 2005. Detecting the number of clusters of individuals using the software STRUCTURE: a simulation study. Molecular ecology 14: 26112620 .

Excoffier L, Laval G, Schneider S. 2005. Arlequin (version 3.0): an integrated software package for population genetics data analysis. Evolutionary bioinformatics 1: 47-50.

Fu YX. 1997. Statistical tests of neutrality of mutations against population growth, hitchhiking and background selection. Genetics 147: 915-925.

Funk DJ, Omland KE. 2003. Species-level paraphyly and polyphyly: frequency, causes, and consequences, with insights from animal mitochondrial DNA. Annual Review of Ecology, Evolution, and Systematics 34: 397-423.

Glaubitz JC. 2004. Convert: a user - friendly program to reformat diploid genotypic data for commonly used population genetic software packages. Molecular Ecology Notes 4: 309-310.

Grandin U. 2006. PC - ORD version 5: A user - friendly toolbox for ecologists. Journal of Vegetation Science 17: 843-844.

Guo WX, Xia ZQ. 2007. Study on ecological flow in the middle and lower reaches of the Yangtze River. Journal of Hydraulic Engineering 10: 618-623.

Holland MM, Parson W. 2011. GeneMarker® HID: A reliable software tool for the analysis of forensic STR data. Journal of forensic sciences 56: 29-35. 
279 Hubisz MJ, Falush D, Stephens M, Pritchard JK. 2009. Inferring weak population structure 280 with the assistance of sample group information. Molecular ecology resources 9: 1322-1332.

Katoh K, Rozewicki J, Yamada KD. 2017. MAFFT online service: multiple sequence alignment, interactive sequence choice and visualization. Briefings in bioinformatics.

Lei L, Feng L, Jian TR, Yue GH. 2012. Characterization and multiplex genotyping of novel microsatellites from Asian swamp eel, Monopterus albus. Conservation genetics resources 4: 363-365.

Li W, Liao X, Yu X, Cheng L, Tong J. 2007. Isolation and characterization of polymorphic microsatellites in a sex-reversal fish, rice field eel (Monopterus albus). Molecular ecology notes 7: 705-707.

Li W, Sun WX, Fan J, Zhang CC. 2013. Genetic diversity of wild and cultured swamp eel (Monopterus albus) populations from central China revealed by ISSR markers. Biologia 68: 727-732.

Liang H, Guo S, Li Z, Luo X, Zou G. 2016. Assessment of genetic diversity and population structure of swamp eel Monopterus albus in China. Biochemical systematics and ecology 68: 81-87.

Liem KF. 1963. Sex reversal as a natural process in the synbranchiform fish Monopterus albus. Copeia 2: 303-312.

Liu CK. 1944. Rudimentary hermaphroditism in the symbranchoid eel, Monopterus favanensis. Sinensia 15: 1-18.

Mazzoni T, Lo Nostro F, Antoneli F, Quagio-Grassiotto I. 2018. Action of the Metalloproteinases in Gonadal Remodeling during Sex Reversal in the Sequential Hermaphroditism of the Teleostei Fish Synbranchus marmoratus (Synbranchiformes: Synbranchidae). Cells 7: 34.

Nelson JS, Grande TC, Wilson MV. 2016. Fishes of the world. John Wiley \& Sons Press. Qu XC. 2018. Sex determination and control in eels. In: Sex Control in Aquaculture. John Wiley \& Sons Press. 775-792. 
307 Qu Y, Zhang R, Quan Q, Song G, Li SH, Lei F. 2012. Incomplete lineage sorting or 308 secondary admixture: disentangling historical divergence from recent gene flow in 309 the $\mathrm{V}$ inous-throated parrotbill (Paradoxornis webbianus). Molecular ecology 21: 6117-6133.

Rogers AR, Harpending H. 1992. Population growth makes waves in the distribution of pairwise genetic differences. Molecular biology and evolution 9: 552-569.

Rozas J, Ferrer-Mata A, Sánchez-DelBarrio JC, Guirao-Rico S, Librado P, Ramos-Onsins SE, Sánchez-Gracia A. 2017. DnaSP 6: DNA sequence polymorphism analysis of large data sets. Molecular biology and evolution 34: 3299-3302.

Saccone C, De Giorgi C, Gissi C, Pesole G, Reyes A. 1999. Evolutionary genomics in Metazoa: the mitochondrial DNA as a model system. Gene 238: 195-209.

Sambrook J, Fritsch EF, Maniatis T. 1989. Molecular cloning: a laboratory manual. Cold spring harbor laboratory press.

Slatkin M, Barton NH. 1989. A comparison of three indirect methods for estimating average levels of gene flow. Evolution 43: 1349-1368.

Suchard MA, Lemey P, Baele G, Ayres DL, Drummond AJ, Rambaut A. 2018. Bayesian phylogenetic and phylodynamic data integration using BEAST 1.10. Virus Evolution 4: vey016.

Tajima F. 1989. Statistical method for testing the neutral mutation hypothesis by DNA polymorphism. Genetics 123: 585-595.

Yang JQ, Hsu KC, Liu ZZ, Su LW, Kuo PH., Tang WQ, Zhou ZC, Liu D, Bao BL, Lin HD. 2016. The population history of Garra orientalis (Teleostei: Cyprinidae) using mitochondrial DNA and microsatellite data with approximate Bayesian computation. $B M C$ evolutionary biology 16: 73.

Yeh FC, Yang RC, Boyle TB, Ye ZH, Mao JX. 1997. POPGENE, the user-friendly shareware for population genetic analysis. Molecular biology and biotechnology centre, University of Alberta, Canada 10: 295-301.

Zarza E, Reynoso VH, Emerson BC. 2011. Discordant patterns of geographic variation 
335 between mitochondrial and microsatellite markers in the Mexican black iguana 336 (Ctenosaura pectinata) in a contact zone. Journal of Biogeography 38: 1394-1405.

337 Zhang W, LI YT, Jiang L. 2008. Fluvial process change of the typical multi-branched 338 meandering reach in the mid-down Yangtze River after three gorges dam 339 impoundment. Journal of Sichuan University (Engineering Science Edition) 40: 1734024.

341 Zhuo Y, Hu H, Zhang L, Shu M. 2011. Microsatellite analysis of genetic diversity of 342 Monopterus albus along the middle and lower reaches of Yangtze River basin. 343 Biotechnology Bulletin 11: 187-192. 
Figure 1

Figure 1. Sampling sites along the Yangtze River mapped using DIVA-GIS.

Sampling sites along the Yangtze River mapped using DIVA-GIS. Three sampling sites from main stem included Wu Wei (WW), Gui Chi (GC) and Wang Jiang (WJ); three sampling sites from tributaries included Dang Tu (DT), Fan Chang (FC) and Huai Ning (HN). FC tributary connected to the main stem during the wet season and isolated during the dry season. Data source: DIVA-GIS (http://swww.diva-gis.org/Data).

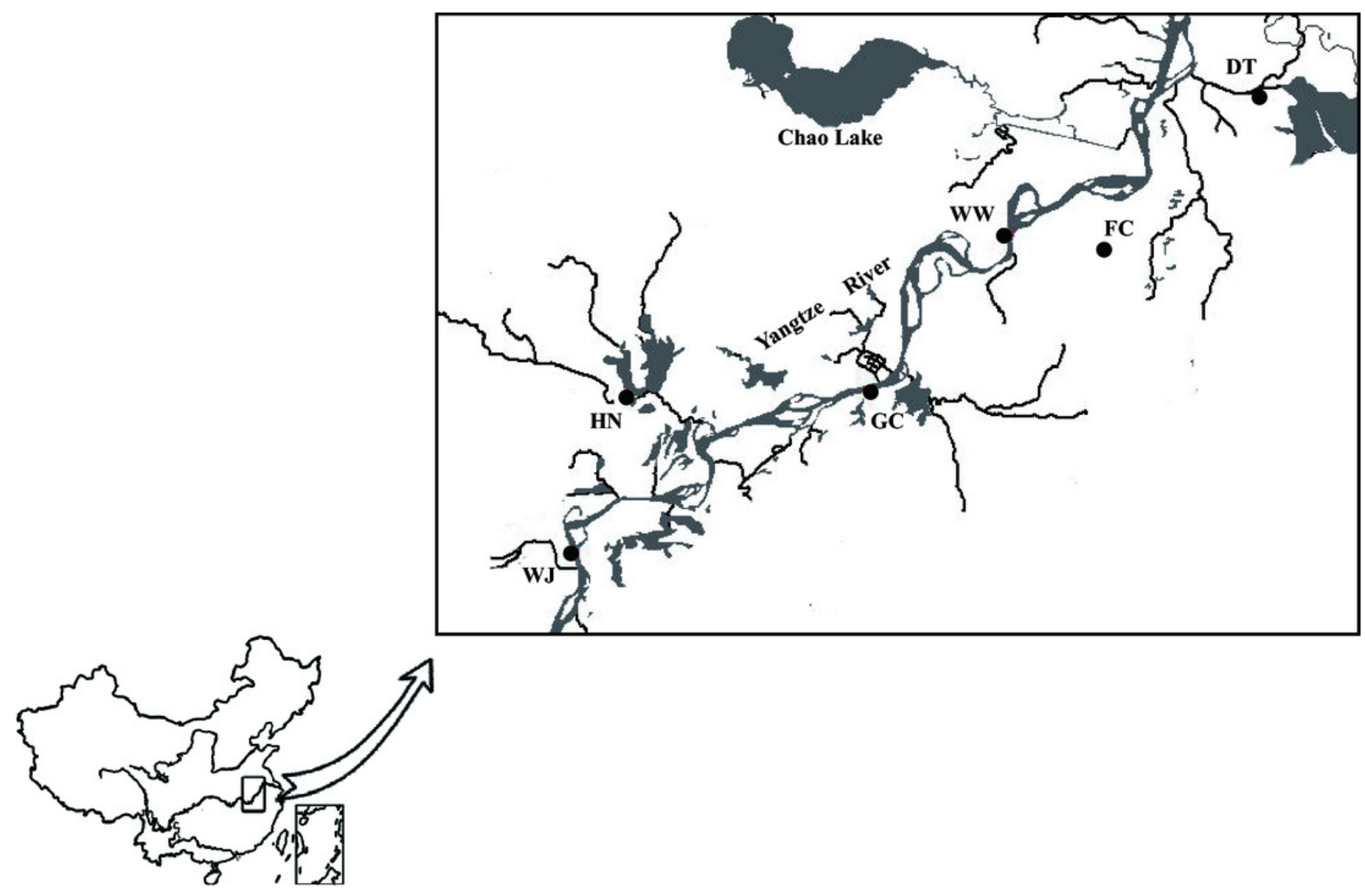




\section{Figure 2}

Figure 2. Haplotype network showing the genetic relationship of samples using Median Joining (MJ) method.

Different colors represent the six populations. Circle size represents the number of sequence. The largest circle represents $n=24$ and the smallest circle represent $n=1$. Numbers of nearby branches represent the mutational steps and no numbers represent only one mutational step. Black dots represent Median Vector (mv). 


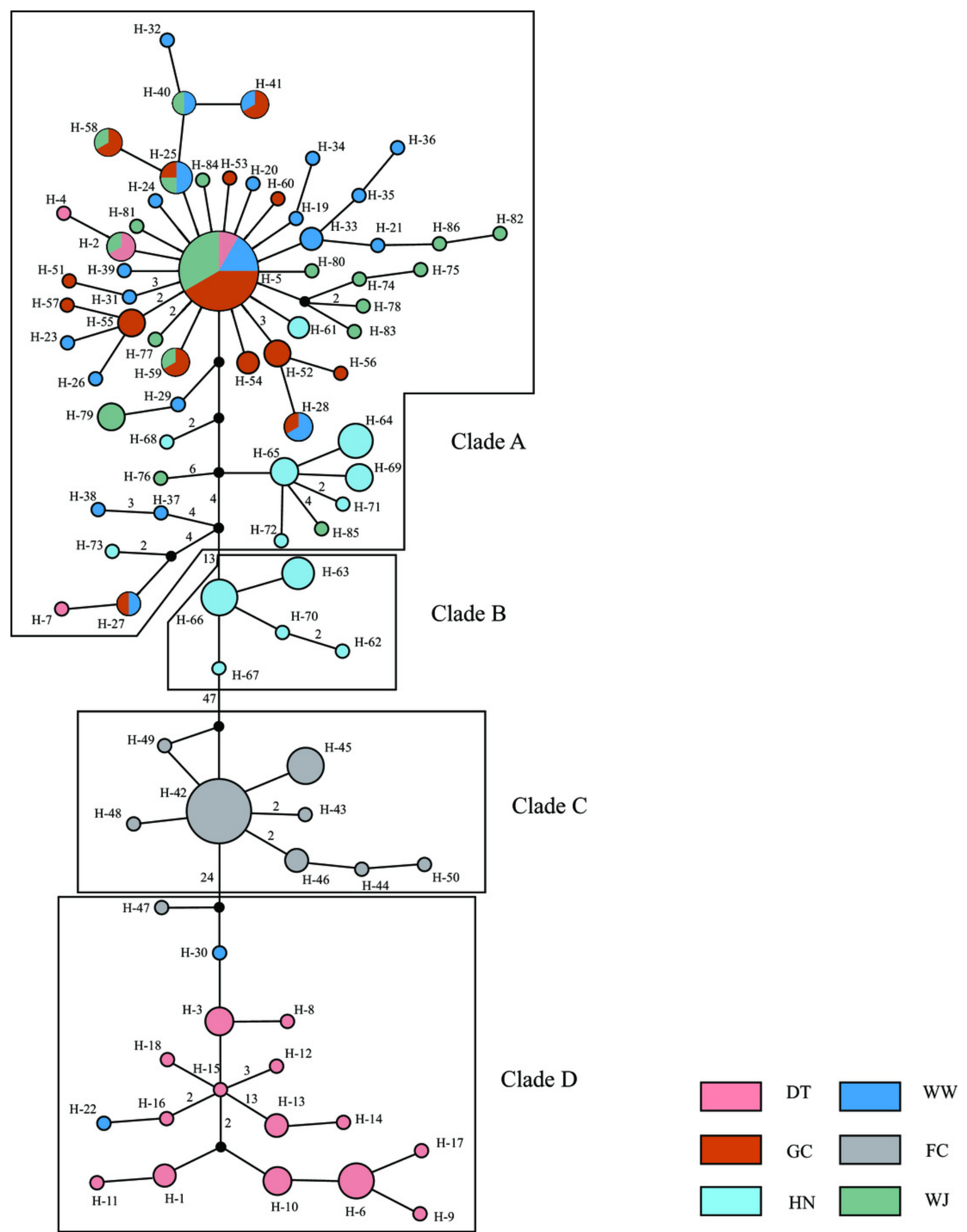




\section{Figure 3}

Figure 3. The demographic history inferred from mitochondrial data.

Samples from three main stem sampling sites were treat as one group. (A) Mismatch distribution of main stem samples; (B) Bayesian skyline plots of main stem samples, the shaded area represents the 95\% confidence intervals of Highest Posterior Density (HPD) analysis; (C) Mismatch distribution of DT samples; (D) Bayesian skyline plots of DT samples; (E) Mismatch distribution of FC samples; (F) Bayesian skyline plots of FC samples; (G) Mismatch distribution of HN samples; (H) Bayesian skyline plots of HN samples. 

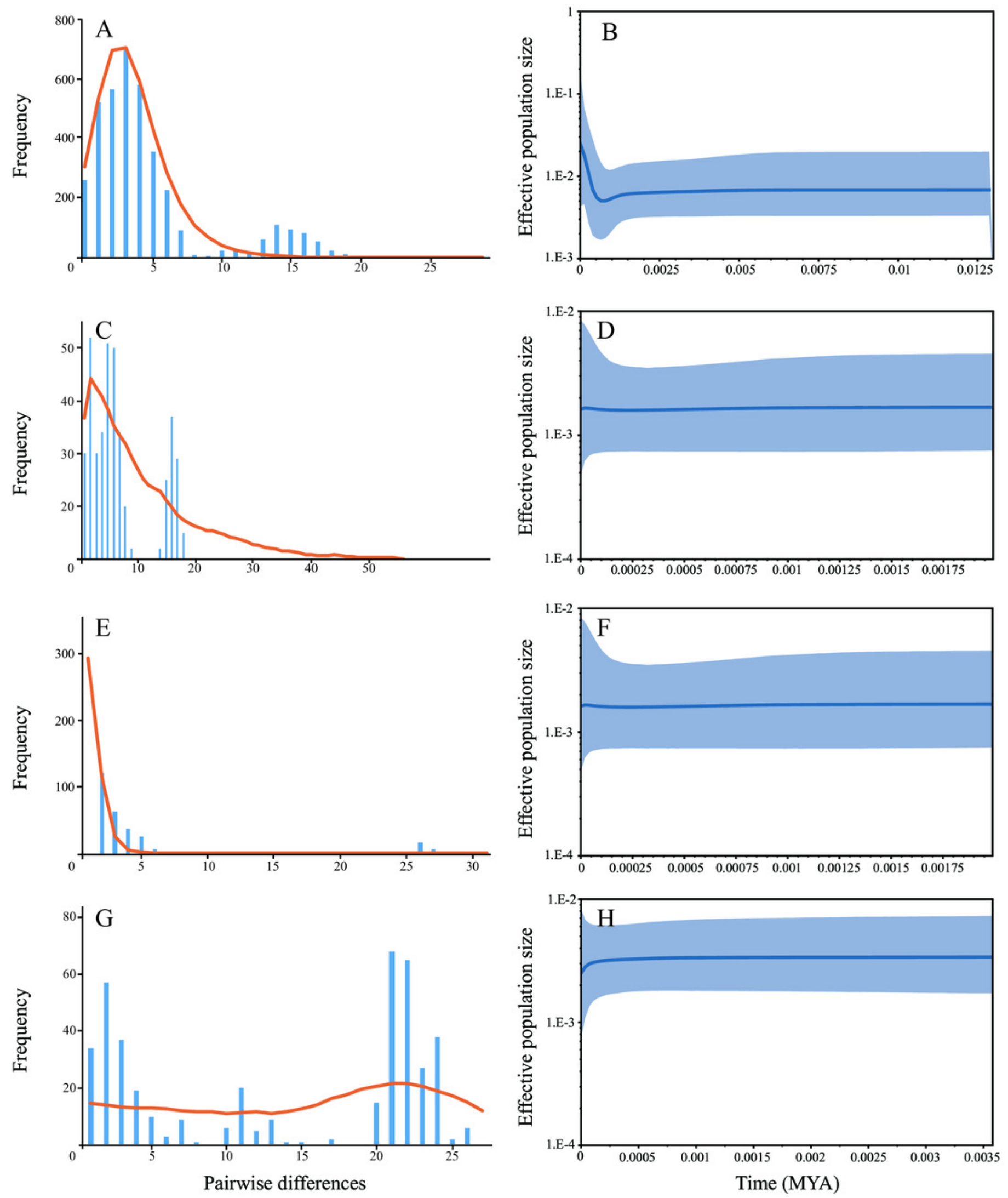
Figure 4

Figure 4. Population structure of 180 swamp eels showing for $\mathrm{K}=4$.

Four colors, e.g., red, yellow, purple and green, represent the inferred genetic clusters.

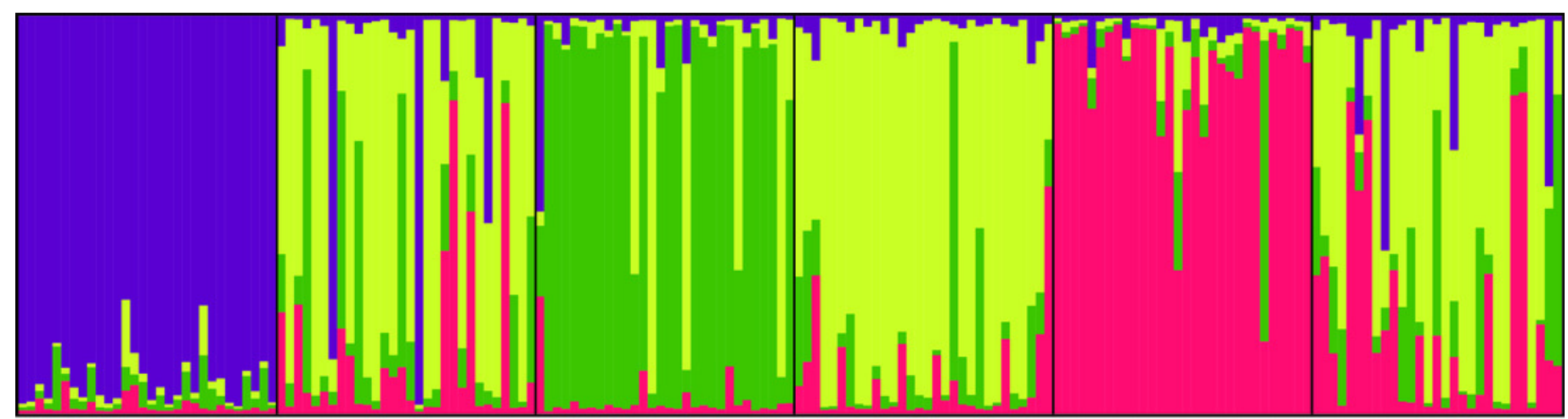<smiles>[C]1CC1</smiles><smiles>[C-]#[C-]</smiles><smiles>[Co]</smiles>

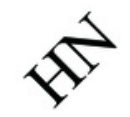

$\mathcal{N}$ 
Figure 5

Figure 5. Plotmatrix indicating the correlation between genetic and geographic matrixes.

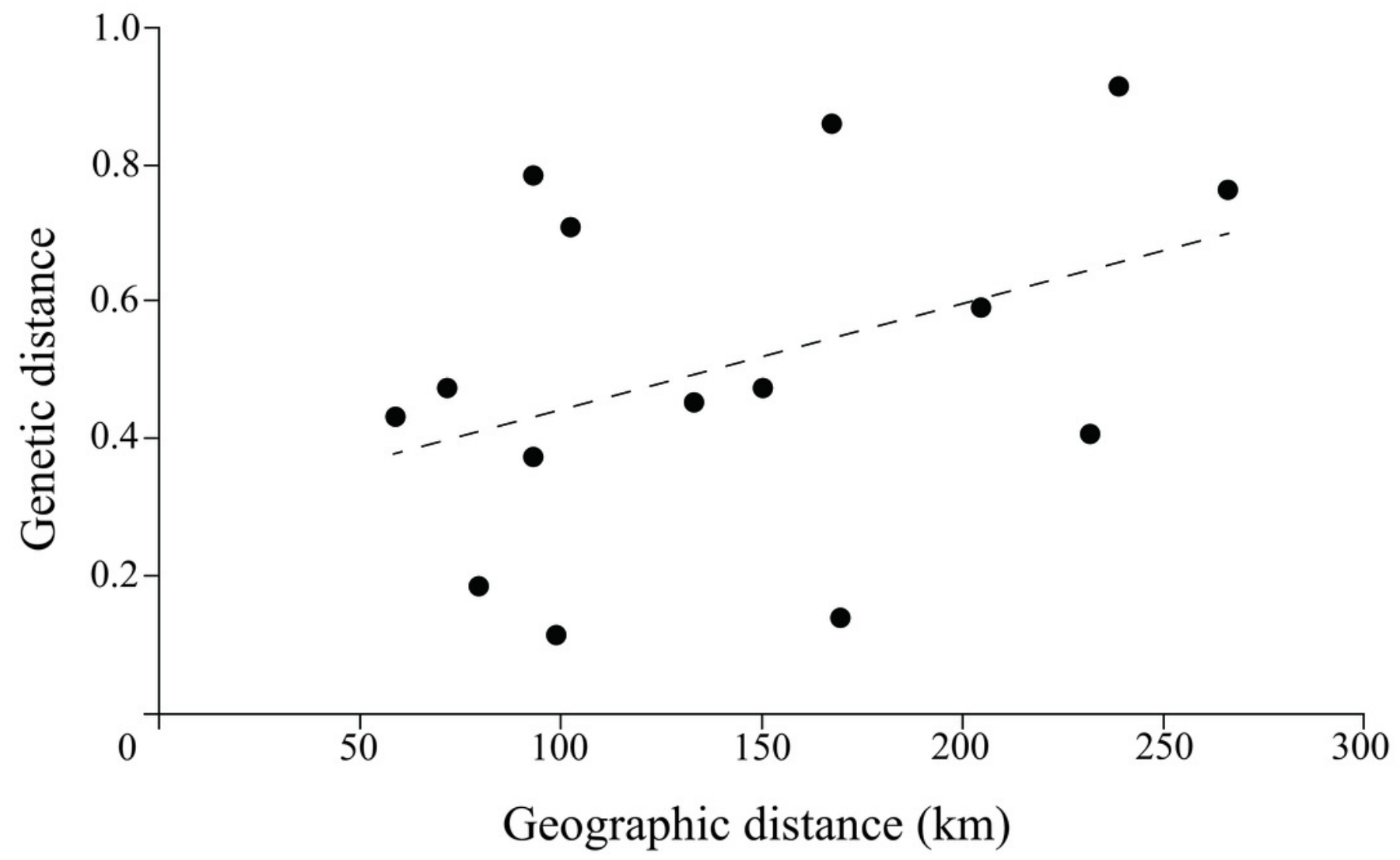


Figure 6

Figure 6. Diagram showing the unique life history and different hereditary patterns of mitochondrial DNA and nuclear DNA in sex reversal fish.
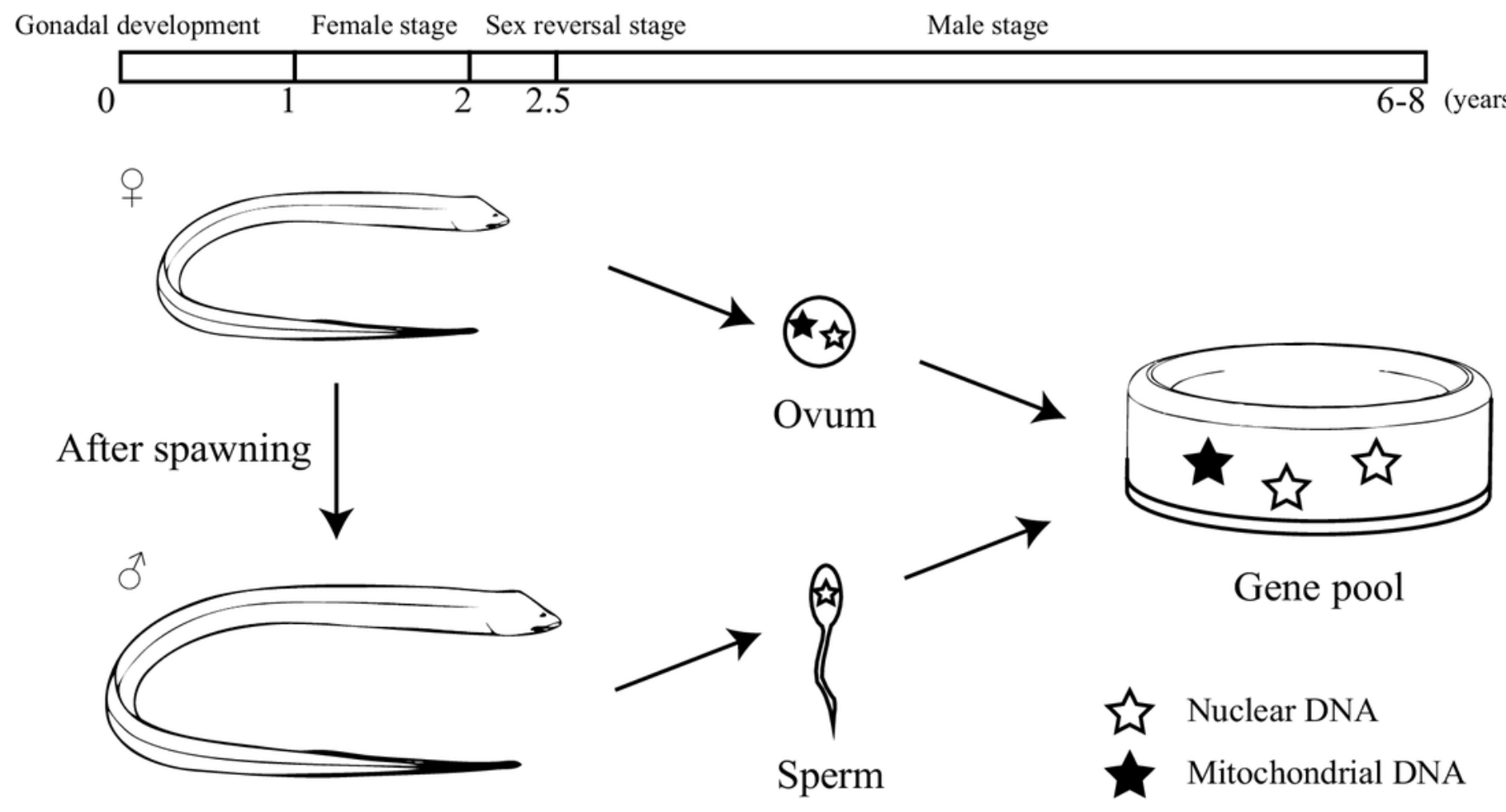

今 Mitochondrial DNA 


\section{Table $\mathbf{1}$ (on next page)}

Table 1. Genetic diversity of samples from six sites assessed using mitochondrial and microsatellite data

Hd represents Haplotype diversity, Pi represents Nucleotide diversity, He represents Expected heterozygosity; Ho represents observed heterozygosity 
1

2

Table 1. Genetic diversity of samples from six sites assessed using mitochondrial and microsatellite data

\begin{tabular}{|l|c|c|c|c|c|c|}
\hline \multirow{2}{*}{ Sampling sites } & \multicolumn{3}{|c|}{ Mitochondrial genes } & \multicolumn{3}{c|}{ Microsatellite loci } \\
\cline { 2 - 7 } & Num. of haplotypes & $H d$ & $P i$ & Num. of alleles & $H e$ & Ho \\
\hline DT (Tributary) & 18 & 0.9540 & 0.0148 & 14 & 0.8749 & 0.7917 \\
\hline WW (main stem) & 24 & 0.9793 & 0.0078 & 14 & 0.8638 & 0.7292 \\
\hline FC (Tributary) & 9 & 0.6620 & 0.0017 & 12 & 0.8089 & 0.6542 \\
\hline GC (main stem) & 15 & 0.8480 & 0.0021 & 13 & 0.8420 & 0.7417 \\
\hline HN (Tributary) & 13 & 0.9220 & 0.0072 & 12 & 0.8052 & 0.5958 \\
\hline WJ (main stem) & 19 & 0.9240 & 0.0023 & 14 & 0.8516 & 0.7802 \\
\hline
\end{tabular}

3 Hd represents Haplotype diversity, Pi represents Nucleotide diversity, He represents Expected heterozygosity; Ho represents observed 4 heterozygosity

5 


\section{Table 2 (on next page)}

Table 2 AMOVA of 6 sampling sites indicating the source of variation 
Table 2a. AMOVA of 6 sampling sites indicating the source of variation by mitochondrial data used

\begin{tabular}{|l|c|c|c|c|}
\hline \multicolumn{1}{|c|}{ Source of variation } & $\mathrm{d} f$ & Sum of squares & Percentage of variation & $P$ value \\
\hline Among sampling sites & 5 & 1965.433 & 71.23 & $<0.001$ \\
\hline Within sampling sites & 174 & 908.533 & 28.77 & $<0.001$ \\
\hline Total & 179 & 2873.967 & & \\
\hline
\end{tabular}

2

Table 2b. AMOVA of 6 sampling sites indicating the source of variation by microsatellite loci used

\begin{tabular}{|l|c|c|c|c|}
\hline Source of variation & $\mathrm{d} f$ & Sum of squares & Percentage of variation & $P$ value \\
\hline Among sampling sites & 5 & 76.325 & 5.35 & $<0.001$ \\
\hline Within sampling sites & 352 & 672.105 & 94.65 & $<0.001$ \\
\hline total & 357 & 1260.43 & & \\
\hline
\end{tabular}

4 


\section{Table 3(on next page)}

Table 3. Pairwise values of $F_{\text {st }}$ (below diagonal) and $P$ (above diagonal) between sampling sites 
Table 3a. Pairwise values of $\boldsymbol{F}_{\text {st }}$ (below diagonal) and $\boldsymbol{P}$ (above diagonal) between sampling sites estimated using

2 mitochondrial data

\begin{tabular}{l|cccccc}
\hline & DT & WW & FC & GC & HN & WJ \\
\hline DT & & $<0.01$ & $<0.01$ & $<0.01$ & $<0.01$ & $<0.01$ \\
WW & 0.6228 & & $<0.01$ & 0.08 & $<0.01$ & 0.05 \\
FC & 0.5800 & 0.8510 & & $<0.01$ & $<0.01$ & $<0.01$ \\
GC & 0.7296 & 0.0242 & 0.9431 & & $<0.01$ & $<0.01$ \\
HN & 0.6441 & 0.3069 & 0.8551 & 0.4750 & & $<0.01$ \\
WJ & 0.7253 & 0.0286 & 0.9391 & 0.0305 & 0.4594 & \\
\hline
\end{tabular}

3

Table 3b. Pairwise values of $F_{\mathrm{st}}$ (below diagonal) and $\boldsymbol{P}$ (above diagonal) between sampling sites estimated using 5 microsatellite loci

\begin{tabular}{l|cccccc}
\hline & DT & WW & FC & GC & HN & WJ \\
\hline DT & & $<0.01$ & $<0.01$ & $<0.01$ & $<0.01$ & $<0.01$ \\
WW & 0.0653 & & $<0.01$ & 0.06 & $<0.01$ & 0.37 \\
FC & 0.0813 & 0.0509 & & $<0.01$ & $<0.01$ & $<0.01$ \\
GC & 0.0794 & 0.0077 & 0.0585 & & $<0.01$ & 0.63 \\
HN & 0.0982 & 0.0597 & 0.0869 & 0.0636 & & $<0.01$ \\
WJ & 0.0704 & 0.0030 & 0.0509 & 0.0005 & 0.0493 & \\
\hline
\end{tabular}

6 
Table 4 (on next page)

Table 4. Summary of neutrality and mismatch analyses indicating the demographic history

$* P<0.05 ; * *<<0.01$ 
1

Table 4. Summary of neutrality and mismatch analyses indicating the demographic history

\begin{tabular}{|l|c|c|c|c|}
\hline Populations & Tajima's $D$ & Fu's $F_{\mathrm{s}}$ & $\tau$ & SSD $(P)$ \\
\hline Main stem & $-2.3328^{* *}$ & $-24.9078^{* *}$ & 2.2949 & $0.0056(0.36)$ \\
\hline DT & 0.6878 & 1.8735 & 0.3906 & $0.0344(0.53)$ \\
\hline FC & $-2.4163^{* *}$ & -0.8094 & 0.375 & $0.1446(0.02)$ \\
\hline HN & 0.4788 & 2.1653 & 22.5293 & $0.0496(0.008)$ \\
\hline
\end{tabular}

